\title{
Non-ketotic hyperosmolar hyperglycemic chorea
}

\author{
(iD) Matheus Ferreira Gomes* \\ (iD) Euripedes Gomes de Carvalho Neto ${ }^{*}$ \\ (iD) Fernando Kowacs ${ }^{2 *}$ \\ (iD) Carlos R. M. Rieder ${ }^{3^{* *}}$
}

* acquisition of data, literature review

** critical revision of manuscript for intellectual content, study supervision 1. Neurology Resident, Irmandade Santa Casa de Misericórdia of Porto Alegre, Federal University of Health Sciences of Porto Alegre, Porto Alegre, Brasil 2. Professor of Neurology, Irmandade Santa Casa de Misericórdia of Porto Alegre, Federal University of Health Sciences of Porto Alegre, Porto Alegre, Brasil 3. Professor of Neurology, Movement Disorders Division, Irmandade Santa Casa de Misericórdia of Porto Alegre, Federal University of Health Sciences of Porto Alegre, Porto Alegre, Brasil

KEYWORDS: Chorea. Dyskinesias. Hyperglycemia.

\section{INTRODUCTION}

Chorea is a type of hyperkinesia characterized by the presence of involuntary, brief and unsustained movements caused by irregular sequential muscle activation that flows continuously in a disorderly and unpredictable way. ${ }^{1}$ It can be a manifestation of a primary neurologic genetic disorder, such as Huntington disease, or may occur as a neurologic complication of a systemic, toxic or metabolic cause, e.g., hypo/hypercalcemia or hyperglycemia. ${ }^{2}$ Bedwell $^{3}$, in 1960, was the first author to describe the rare clinical syndrome of nonketotic hyperosmolar hyperglycemic (NKHH) chorea. Although rare, it is a treatable condition and, therefore, should be recognized.

\section{OBJECTIVES}

To describe the clinical presentation and neuroradiologic findings of a typical case of NKHH chorea.

\section{CASE}

An 80-year-old man was admitted after the abrupt onset of involuntary movements that affected his whole body three months before admission. Medical history revealed diabetes mellitus and systemic arterial hypertension with irregular follow-up and poor glycemic control.

Neurological examination showed orofacial dyskinesias and gait associated choreoatheteroid move- 

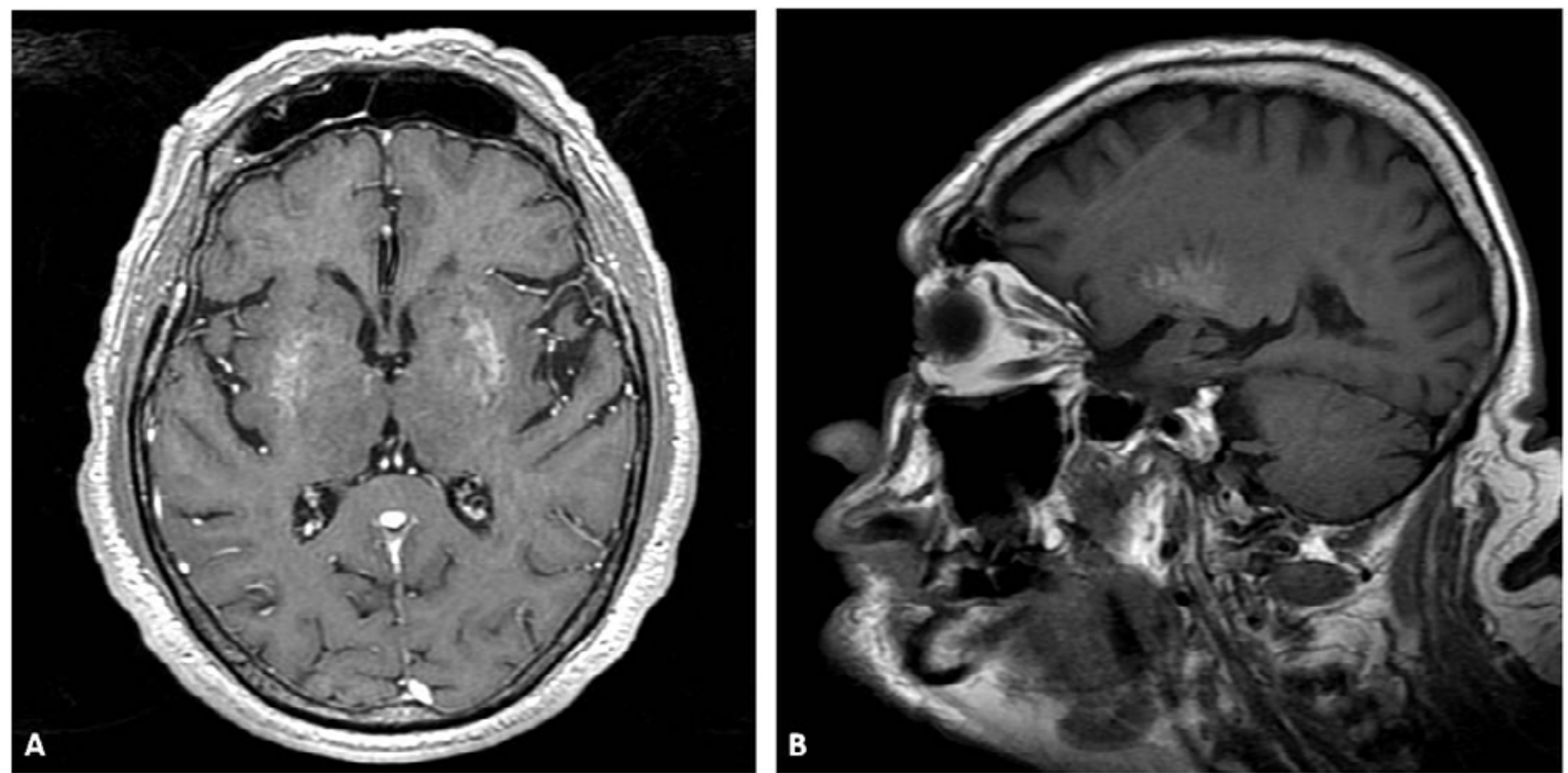

FIGURE. AXIAL (A) AND SAGITTAL (B) T1-WEIGHTED IMAGES SHOWING BILATERAL SPONTANEOUS HYPERINTENSE AREAS IN THE BASAL GANGLIA

ments affecting mainly the left lower limb. Hemoglucotest was $462 \mathrm{mg} / \mathrm{dL}$ on admission and brain MRI showed non-specific hyperintense areas in the basal ganglia on T1 (FIGURE).

The diagnosis of chorea secondary to nonketotic hyperosmolar hyperglycemic state was established through clinical and imaging findings, and the patient was managed with intensive diabetes control and haloperidol $5 \mathrm{mg}$ orally twice daily. There was a remarkable improvement in the next few days, and the patient was subsequently discharged with almost no symptoms.

\section{DISCUSSION}

Chorea pathophysiology is still not widely understood. However, unlike in parkinsonism and dystonia, intracortical inhibition of the motor cortex is normal. ${ }^{4}$ Semiquantitative analysis of single photon emission computed tomography in patients with hemichorea due to various causes suggests that there is an increase in activity in the contralateral thalamus, possibly due to disinhibition as a result of loss of normal pallidal inhibitory input. ${ }^{5}$

Non-ketotic hyperglycemia-induced chorea occurs more often in women and is usually associated with very high blood glucose ${ }^{6}$. The exact pathophysiology of NKHH chorea remains unclear. However, many hypotheses as blood hyperviscosity, petechial hemorrhage, depletion of gamma-aminobutyric acid (GABA) and cerebral vascular insufficiency have been suggested. ${ }^{7}$ The correction of the metabolic abnormality usually is curative, but it can rarely continue for months after resolution of hyperglycemia. ${ }^{8}$ Striatal permanent vascular changes may mean persistence of chorea for long periods. ${ }^{9}$

Many of the metabolic choreas are associated with abnormalities on MRI scans. Nevertheless, the etiology of the MRI changes is not fully understood. ${ }^{10}$ Hepatocerebral degeneration and hyperglycemic chorea are often associated with high signal intensity on T1-weighted MRI involving the striatum and pallidum. ${ }^{8}$

Chu et al. ${ }^{11}$, in a report of two patients with hyperglycemic hemichorea-hemiballism, found high signal intensities on T1- and T2-weighted images as well as on diffusion-weighted MRI accompanied by a reduction in diffusion coefficient, suggestive of hyperviscosity, rather than petechial hemorrhages, as the mechanism of edema in the striatum. This is also corroborated by another study of seven patients with hyperglycemic choreoathetosis using MRI and MR spectroscopy. ${ }^{12}$ Interestingly, the presence of high counts of acanthocytes may predispose patients with diabetes to develop hyperglycemic chorea. ${ }^{13}$ 


\section{CONCLUSION}

A thorough physical examination and compatible clinical history and imaging are essential tools for diagnosing and treating metabolic chorea. In this case of symptoms secondary to diabetes decompensation,

PalaVRas ChaVE: Coreia. Discinesias. Hiperglicemia.

\section{REFERENCES}

1. Cardoso F, Seppi K, Mair KJ, Wenning GK, Poewe W. Seminar on choreas. Lancet Neurol. 2006;5(7):589-602.

2. Cardoso F. Chorea: non-genetic causes. Curr Opin Neurol. 2004;17(4):433-

3. Bedwell SF. Some observations on hemiballismus. Neurology 1960;10:619-22.

4. Hanajima R, Ugawa Y, Terao Y, Furubayashi T, Machii K, Shiio Y, et al. Intracortical inhibition of the motor cortex is normal in chorea. J Neurol Neurosurg Psychiatry. 1999;66(6):783-6.

5. Kim JS, Lee KS, Lee KH, Kim YI, Kim BS, Chung YA, et al. Evidence of thalamic disinhibition in patients with hemichorea: semiquantitative analysis using SPECT. J Neurol Neurosurg Psychiatry. 2002;72(3):329-33.

6. Oh SH, Lee KY, Im JH, Lee MS. Chorea associated with non-ketotic hyperglycemia and hyperintensity basal ganglia lesion on T1-weighted brain MRI study: a meta-analysis of 53 cases including four present cases. ) Neurol Sci. 2002;200(1-2):57-62.

7. Abdelghany M, Massoud S. Nonketotic hyperglycemic chorea. Case Rep Neurol Med. 2014;2014:128037. glycemic control added to a central dopaminergic inhibitor were effective.

\section{Authors Disclosures}

No conflict of interest to disclose.
8. Ahlskog JE, Nishino H, Evidente VG, Tulloch JW, Forbes GS, Caviness JN, et al. Persistent chorea triggered by hyperglycemic crisis in diabetics. Mov Disord. 2001;16(5):890-8.

9. Walker RH. Differential diagnosis of chorea. Curr Neurol Neurosci Rep. 2011;11(4):385-95

10. Stanley F, Jankovic, J, Hallett M. Principles and practice of movement disorders. $2^{\text {nd }}$ ed. Saunders; 2011.p.335-48.

11. Chu K, Kang DW, Kim DE, Park SH, Roh JK. Diffusion-weighted and gradient echo magnetic resonance findings of hemichorea-hemiballismus associated with diabetic hyperglycemia: a hyperviscosity syndrome? Arch Neurol. 2002;59(3):448-52.

12. Kandiah N, Tan K, Lim CC, Venketasubramanian N. Hyperglycemic choreoathetosis: role of the putamen in pathogenesis. Mov Disord. 2009;24(6):915-9

13. Pisani A, Diomedi M, Rum A, Cianciulli P, Floris R, Orlacchio A, et al. Acanthocytosis as a predisposing factor for non-ketotic hyperglycemia induced chorea-ballism. I Neurol Neurosurg Psychiatry. 2005;76(12):1717-9 